\title{
Interference competition as a key determinant for spatial distribution of mangrove crabs
}

\author{
Stefano Cannicci ${ }^{1,2}$, Marco Fusi ${ }^{3}$, Filippo Cimó ${ }^{2}$, Farid Dahdouh-Guebas ${ }^{4,5,6}$ and Sara Fratini ${ }^{2,6^{*}}$ (i)
}

\begin{abstract}
Background: The spatial distribution of mangrove crabs has been commonly associated with tree zonation and abiotic factors such as ground temperature and soil granulometry. Conversely, no studies were designed to investigate the role of competition for resources and predation in shaping crab distribution in mangroves, despite these biotic factors are recognised as key determinants for spatial patterns observed in the communities colonising rocky and sandy intertidal habitats. We studied floral and faunal assemblages in two zones of a Sri Lankan mangrove, a manmade upper intertidal level and a natural eulittoral, mid-shore one. Leaf choice experiments were designed to study both feeding rate and intra and inter-specific interactions for food of sesarmid crabs in the two habitats in order to better understand crab spatial distribution.

Results: The two intertidal belts differed in terms of floral composition and crab species abundance. The eulittoral zone was strongly dominated by Neosarmatium smithi, while within the elevated littoral fringe four sesarmids ( $N$. smithi, N. asiaticum, N. malabaricum and Muradium tetragonum) were more evenly distributed. At both levels, all sesarmids showed to collect significantly more Bruguiera spp. and Rhizophora apiculata leaves than Excoecaria agallocha ones. There was no temporal segregation in feeding activity among the four species, resulting in a high interference competition for leaves. Regardless of the habitat, N. smithi was always successful in winning inter-specific fights.

Conclusions: Our results showed that the elevated littoral fringe was more crowded with crabs, but was less favourable in terms of food availability and environmental conditions. The dominance of N. smithi in gathering mangrove leaves suggests that this species may segregate the other sesarmids into less favourable habitats. The present data strongly suggest for the first time that interference competition for food can contribute to shape mangrove crab spatial distribution.
\end{abstract}

Keywords: Sesarmid crabs, Aggressive behaviour, Distribution patterns, Indo-Pacific mangroves, Environmental factors

\section{Background}

Indo-Pacific mangrove forests host abundant populations of molluscs and crabs, both critically important taxa in energetics and food web [1-3]. Respect to molluscs, brachuyuran crabs are also extremely diverse in terms of genera and species [3]. In the Indian subcontinent, for

\footnotetext{
*Correspondence: sarafratini@unifi.it

${ }^{2}$ Department of Biology, University of Florence, via Madonna del Piano 6, 50019 Sesto Fiorentino, Italy

Full list of author information is available at the end of the article
}

instance, 149 species, belonging to 75 genera were found living in mangroves [4], while over a hundred species are known to colonise mangroves of the peninsular Malaysia [5]. This rather diverse crab fauna exhibits some degrees of spatial segregation that is often related to intertidal zones, similarly to what can be observed on less spatially complex intertidal habitats $[6,7]$. This view was developed after the classical studies by Macnae [6], Sasekumar [8] and Hartnoll [9], who divided the mangrove forests in major zones differing in terms of tidal level, inundation time, floral composition and soil texture and described crab assemblages 
typical of each zone. Since those papers, a considerable amount of literature confirmed the distribution patterns of the Indo-Pacific mangrove crabs [10-13] gathering a huge amount of descriptive data on brachyuran zonation in mangroves. However, very few studies paralleled these qualitative analyses with sound quantitative or experimental approach aimed at testing which environmental factors can affect the spatial distribution of the different species. In addition, most of these few studies dealt only with the fiddler crabs, genus Uca sensu lato [14], whose distribution patterns are thought to be controlled by their differential resistance to high temperatures [11, 15-17] and by their morphological specialisation for deposit-feeding, resulting in a substratum-dependent spatial segregation $[10,18,19]$.

On the other hand, factors affecting sesarmid crab distribution were rarely addressed, even if these crabs are by far the most abundant and biodiverse macrobenthic taxon within the mangroves and they proved to be very important species in terms of litter consumption [e.g. 20-22], ecosystem engineering [3, 23-27] and propagule predation [28-31].

Observations on species distribution and spatial segregation along the forest, coupled with data on their feeding preferences, suggested a strong correlation between the presence of some major litter consumers, such as the crabs of the Indo-Pacific genus Neosarmatium, and the presence of their preferred trees [6,7]. In this view, the patterns of tree distribution present in various part of the Indo-Pacific region was hypothesised to be the principal drivers of sesarmid crab distribution. Cannicci et al. [3] and Dahdouh-Guebas et al. [32] suggested that crab distribution is the result of a complex interaction between different biotic and abiotic environmental factors, while Paula et al. [33] stressed the importance of the effects of stratified larval recruitment and competence in their distribution. Therefore, no specific hypotheses were formulated on the influence of factors such as competition for resources and predation, known to be key determinant of zonation in other intertidal environments [34-36].

Competition for resources (e.g. food, mates and space) is a major regulatory factor of population dynamics and structure. Competition among foragers can be exploitative, when it is an indirect competition by reducing available food items [37]. Conversely, it is referred to as interference competition when foragers directly interact to access food [37, 38]. Interference competition has been commonly observed in nature either at intra- and inter-specific level and generally is reported as asymmetric, with superior individuals gaining more resources and segregating inferior individuals to less favourable sites [39]. Therefore, the distribution and structure of local populations can be theoretically affected by both exploitative and interference competition as discussed in Fretwell and Lucas [40]. The consequences of interference competition remain however poorly understood [see 39].

Within this framework, sesarmid crab populations are ideal systems to test hypotheses on the effect of inter-specific competition on their distribution within mangroves. In mangroves, in fact, many closely related species live in sympatry, share the same activity windows, have access to the same limited food resource (i.e. leaf litter) and indirectly and directly compete, at intra- and inter-specific level, for food [21, 41]. Fratini et al. [21], for example, studied the feeding behaviour of mangrove crabs in a high competitive environment, and found that one species adopted the strategy of stealing leaves from foraging individuals belonging to smaller species. However, the authors never investigated the effect of such competition for food on species distributions [21].

Herein we report the results of a series of measures of environmental parameters, field observations and feeding experiments addressing the role of interference competition in the spatial distribution of litter-feeding crabs of the genera Neosarmatium and Muradium (e.g. the most relevant species feeding on mangrove fallen leaves in the Indo-Pacific mangroves) within a Sri Lankan mangrove forest. This study took advantage of intrinsic natural environmental differences in terms of abiotic factors and community composition characterising different zones of the study site. Although resource competition is historically well-recognised as an important factor shaping intertidal community organization [42], this is the first experimental attempt aimed at assessing the role of inter-specific interference competition for food in mangrove crab distribution.

\section{Methods}

\section{Study area and experimental sites}

All observations, records and experiments were carried out at a mangrove forest located in southern Sri Lanka, between Galle and Unawatuna $\left(06^{\circ} 01^{\prime} \mathrm{N}, 80^{\circ} 14^{\prime} \mathrm{E}\right)$. This mangrove, situated in the wet climate zone of Sri Lanka (Fig. 1), is located at about $600 \mathrm{~m}$ from the Indian Ocean. It covers a surface of $1.5 \mathrm{~km}^{2}$ and two rivers run through the mangrove forest: the Thalpe Ela, discharging into the ocean, and the Galu Ganga, a tributary of the former.

The dominant tree species composing the forest are Bruguiera gymnorrhiza, B. sexangula, Excoecaria agallocha, Heritera littoralis and Rhizophora apiculata [43, 44]. The vegetation structure of this forest changed various times since the 1950s due to major human activities carried out both within and around the mangrove [43, 4547 ] and to the indirect effect on the potential predation on propagules by crabs [32]. One of the most impacting infrastructures was built in 1982, when the Galu Ganga 


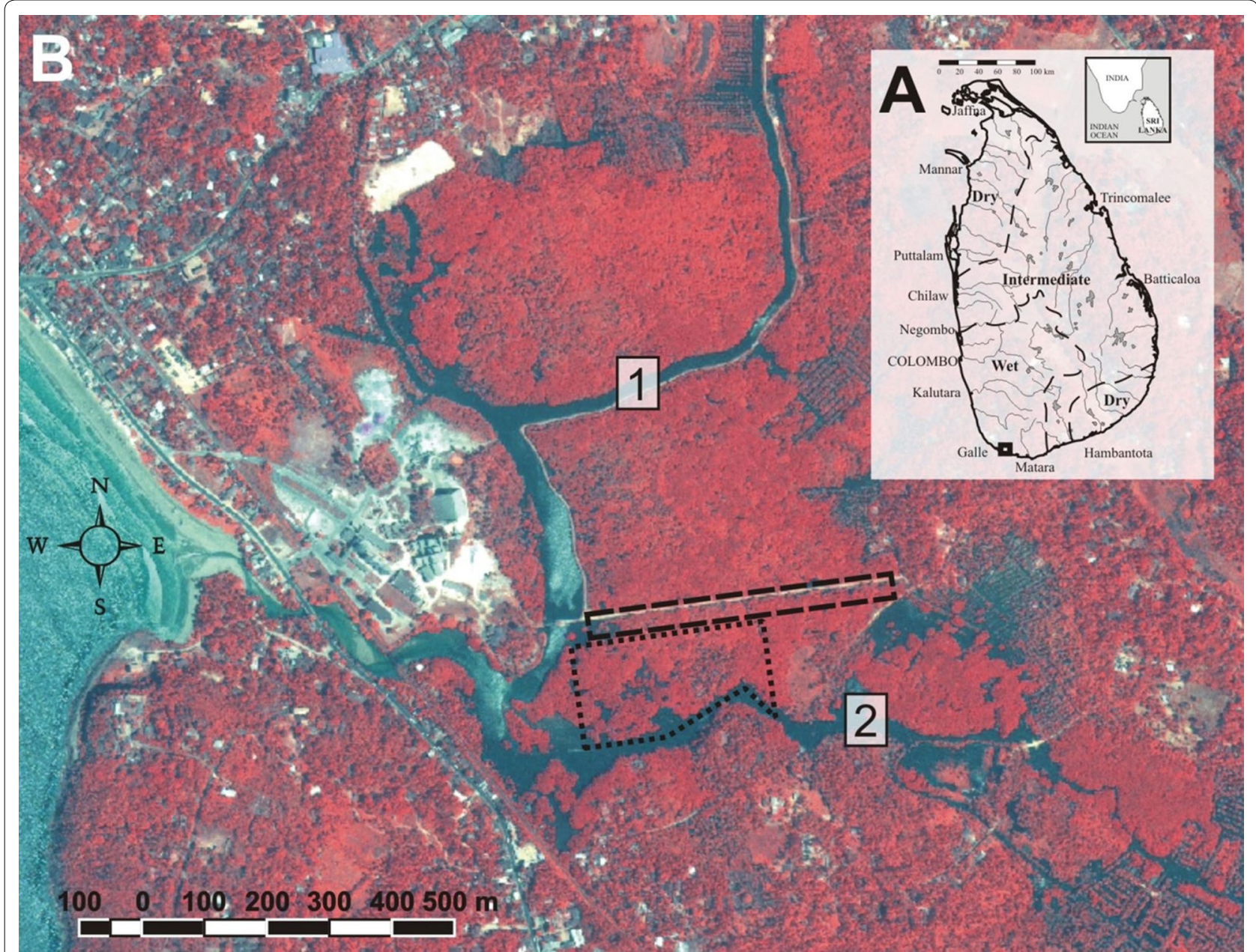

Fig. 1 A Map of Sri Lanka, indicating the major cities, rivers and climatic zones (adapted from [44]). The small black box represents the area in B. B Satellite image of the study area (2004), indicating sampling sites (adapted from [47]). The dashed black box represents the littoral fringe adjacent to the raised motorable track, whereas the dotted black box represents the mangrove forest interior. Numbers 1 and 2 indicate, respectively Galu Ganga and Thalpe Ela

was deepened and broadened: the sediment of the river was used to construct an earthen road that follows the river and continues through the mangrove forest, at an average height of $50 \mathrm{~cm}$ above the mean sea level (Fig. 1).

At the southern Sri Lanka coast, the spring tidal amplitude is less than $1 \mathrm{~m} \mathrm{[48]} \mathrm{and} \mathrm{can} \mathrm{change} \mathrm{as} \mathrm{little} \mathrm{as}$ $15 \mathrm{~cm}$ per week throughout the year in the studied area [43]. Thus, a true tree zonation guided by the tide is virtually absent. However, the forest is an uneven mosaic of shallow ponds and small emerged patches of sediment, primarily resulting from the burrowing activities of the mangrove mud lobsters (Thalassina anomala), which are often occupied by the more terrestrial species Excoecaria agallocha and the mangrove associate Acrostichum aureum on the top, and Rhizophora apiculata at the margin [49].
The macrobenthic community colonising the mangrove is mostly represented by sesarmid crabs and the potamidid gastropod Terebralia palustris [32]. Although the relative frequency of crab species can change in the distinct parts of the forest, the most common crab species are Neosarmatium smithi, N. malabaricum, N. asiaticum (formerly N. meinerti) [50, 51], Muradium tetragonum, Perisesarma dusumieri, Parasesarma bengalense and $P$. plicatum. Crab species of the genera Neosarmatium and Muradium feed on fallen leaves, collect them and store litter into their burrows, enhancing the carbon sink function of mangrove forests soils [31].

Within the studied mangrove area, we selected two areas under different inundation regimes and with diverse granulometry of the soil. The first area was located within the natural mangrove area (henceforth 
referred to as the natural forest floor, FF), while the second one was a new portion of the forest, near the road bed, colonised by the mangrove flora and fauna over the last 20 years (henceforth referred to as the elevated manmade littoral fringe, ELF). The ELF differs from the FF for the granulometry of the soil, since it was built using the sediment from the river. Moreover, and in terms of inundation time, the ELF is seldom and unpredictably covered by water mainly during rainy seasons [32].

\section{Characterisation of abiotic factors and biotic assemblages at the two experimental sites}

Field sampling and observations were performed during the wet season (July to August) when the crab activity is more relevant. Twenty $2 \mathrm{~m} \times 2 \mathrm{~m}$ plots were randomly selected in both sites and the trees present recorded.

The presence and relative abundance of crab species of the genera Neosarmatium and Muradium were assessed using the field techniques described by Skov et al. [52] for large burrowing sesarmid species. All crab burrows present in the plots were recorded and attributed to the different species. Burrows of $M$. tetragonum were easy to distinguish from the Neosarmatium ones: the latter start with funnels almost vertical to the soil surface, whereas the former had the first part of the burrows built at very narrow angles to the soil surface. The burrows of $N$. malabaricum were easily attributed using the diameter of the aperture of the entrance. The average carapace width of $N$. malabaricum is smaller $(\mathrm{CW} \pm \mathrm{SD}=23 \pm 1 \mathrm{~mm})$ than either $N$. asiaticum (CW $36 \pm 4.2 \mathrm{~mm}$ ) or N. smithi (CW $36 \pm 3.1 \mathrm{~mm})$, thus the size of the entrance could identify the smaller species. However, for both the smaller and the larger Neosarmatium burrows, their number was crosschecked with visually counted crabs, at their peaks of activity, during various days to identify the residents for each burrow [52].

As environmental factors, we recorded tree canopy cover, soil granulometry, surface salinity and temperature, since these factors have been reported to affect crab assemblages [7]. A digital camera was placed on the ground at the centre of each plot and a picture of the canopy cover was taken. In the picture, the extent of the plot was delimited using poles placed at its corners and visible in the picture. Each picture was then analysed using the software ImageJ, to assess the total tree cover and percentage contribution of each tree species. Soil cores ( $5 \mathrm{~cm}$ wide, $20 \mathrm{~cm}$ deep) were collected from a subsample of 5 plots in each site and analysed for grain size distribution and organic content following standard procedures [53]. For each core, a sample of $100 \mathrm{~g}$ wet weight was dried and sieved following standard protocols, and median particle diameter, quartile deviation and skewness were calculated. For organic content, a sample of
30-50 g wet weight was dried, weighed, and then incinerated in a muffle furnace at $500^{\circ} \mathrm{C}$ for $24 \mathrm{~h}$ and reweighed. The salinity of pore water and of permanent pools adjacent to the 20 plots was assessed using a salinity refractometer (Atago). The temperature of the soil surface was measured in a subsample of five randomly chosen plots during two $24 \mathrm{~h}$ cycles.

\section{Feeding experiments and behavioural observations on crab species}

Feeding experiments and behavioural observations on intra- and inter-specific competitive interactions were carried out in 20 randomly selected $4 \mathrm{~m}^{2}$ plots at both the ELF (a stretch of about $30,000 \mathrm{~m}^{2}$ near the man-made road, Fig. 1) and FF (an area of about $70,000 \mathrm{~m}^{2}$ inside the forest, Fig. 1) sites. Before starting an experimental session, all existing fallen leaves were carefully removed to standardise food availability and quality in each experimental plot. Then, ten green fresh leaves, i.e. directly collected from the branches of each of the three most abundant mangrove trees (i.e. Bruguiera spp., R. apiculata and $E$. agallocha) were randomly put within each plot and their fate was followed for one hour. During each observation session, two different observers, placed up on the trees or behind the Thalassina anomala mounds not to disturb the crabs, recorded the following data: (1) the time at which each leaf was collected by a crab, (2) the crab species collecting the leaf, (3) every intra- and interspecific encounter and conflict, (4) the species of the crabs involved in this encounter, (5) the final winner, and (6) the total number of crabs observed. For 15 days, these experiments were repeated five times per day at different times of the day (day, night and twilight) for a total of 75 observation sessions per site. At both night and twilight, the observations were carried out with the help of red beam flashlights, in order to not disturb the active animals [54].

\section{Statistical analysis}

The differences in grain size composition between the two intertidal belts were tested by mean of two-way permutational analysis of variance (PERMANOVA) [55], with intertidal belt and grain size categories as orthogonal and fixed factors. A set of three independent estimates of weights of single grain category from various plots was utilised.

Differences in total tree cover, total crab densities and densities of each species between the two belts were tested by univariate and multivariate PERMANOVA one-factor designs. In all cases, similarity matrixes were computed using Bray-Curtis distance on forth-root transformed data, since Levene test revealed heteroscedasticity of data. The contribution of the various species 
of trees and crabs to the differences found between belts was assessed using the SIMPER test.

A univariate PERMANOVA two-factor full factorial design with experimental site (fixed and orthogonal) and time of the day (fixed and orthogonal), was used to test differences in feeding activity, i.e. number of crabs recorded to collect leaves. The observations were divided into three temporal groups: night, day, and a group comprising dawn and dusk periods (i.e. twilight). The amount of leaves collected within $1 \mathrm{~h}$ of observation at the different sites and in different times of the day, both factors fixed and orthogonal, was tested using a two-way univariate PERMANOVA design. To test for differences in leaves removal among species, an ANOVA three-factor design was used, with all three factors (leaf species, habitat and period of the day) fixed and orthogonal. Since the data recorded for the three different leaf species on a same plot were dependent, for every period of the day we picked up at random the data on a single leaf species from five plots and disregarded the data of the other two species. Then, a $\chi^{2}$ test was applied to compare the frequency distribution of the inter-specific interactions won by each species.

Multivariate analyses were performed using the PERMANOVA+ routines for PRIMER 7 and were based on 9999 permutations [56, 57], while univariate analyses (ANOVAs and $\chi^{2}$ test) were performed using GMAV 6 program (University of Sydney, Australia) and PAST v. 2.14 [58]. In the text, results are expressed as average \pm SE.

\section{Results}

\section{Characterisation of abiotic factors and biotic assemblages} at the two experimental sites

The grain size composition was significantly different between the two areas (interaction factor site $\times$ grain size category Pseudo- $\mathrm{F}=4.77, \mathrm{df}=2, \mathrm{p}=0.03$; PERMANOVA test, Fig. 2a). In particular, the soil at the FF area showed a higher amount of medium-sized sand with respect to both coarse and fine sand $(t=12.82, p<0.001$ and $\mathrm{t}=5.35, \mathrm{p}<0.01$, respectively, post hoc test), while the soil in the ELF was composed almost equally by very fine, medium and coarse sand (Fig. 2a). The pore water and the water contained in the permanent pools at both the sites never reached more than $1 \%$ of salinity, a condition typical of the wet season in this area [12].

The floral composition was different between the two sites (Pseudo- $\mathrm{F}=33.36, \mathrm{df}=1, \mathrm{p}<0.001$; PERMANOVA test, Fig. 2b). Bruguiera spp. dominated the FF area while it was not abundant at the ELF (average abundances 56.98 and 6.48 , respectively, contribution to dissimilarity 44.26\%, SIMPER test, Fig. 2b). E. agallocha was not abundant in the FF, but it was dominant at the ELF (average abundances 16.36 and 67.06, respectively, contribution to dissimilarity $44.21 \%$, SIMPER test, Fig. 2b); R. apiculata was always the less common tree species and there was no difference between the two belts (Fig. 2b).

The total tree cover was also different between the two intertidal belts (Pseudo-F $=4.15 ; \mathrm{df}=1 ; \mathrm{p}=0.011$, PERMANOVA), with the FF more shaded than the ELF $(91.34 \% \pm 1.15$ and $81.88 \% \pm 3.87$, respectively). This difference in tree cover affected the temperature of the soil surface: under the forest the average surface temperature during the day was $28.88^{\circ} \mathrm{C} \pm 0.30$, while in the ELF the average temperature was $29.53{ }^{\circ} \mathrm{C} \pm 0.38$ (Fig. 2c).

The total abundance of crab species was significantly higher at the ELF than in the FF $(20.31 \pm 1.37$ and $15.30 \pm 1.01$, respectively, Pseudo-F $=4.97, \mathrm{df}=1$, $\mathrm{p}=0.025$; PERMANOVA test) and the relative frequency of the diverse species was different (Pseudo-F $=53.45$, $\mathrm{df}=1, \mathrm{p}<0.001$; PERMANOVA test) (Fig. 2d). The dominant species at the FF was $N$. smithi, being $85.9 \%$ of the recorded crabs, and it was far more common than at the ELF (average abundances $13.14 \mathrm{ind} / \mathrm{m}^{2}$ and $4.59 \mathrm{ind} / \mathrm{m}^{2}$, respectively, contribution to dissimilarity $23.71 \%$, SIMPER test) (Fig. 2d). On the other hand, M. tetragonum, $N$. malabaricum and $N$. asiaticum were more common at ELF than at FF. At the ELF, $N$. asiaticum outnumbered the other species, representing up to $42.2 \%$ of the total crabs and contributing to the dissimilarity between the two by $33.45 \%$ (SIMPER test) (Fig. 2d).

\section{Feeding experiments and behavioural observations on crab species}

The number of feeding individuals belonging to the four focal species was proportional to their densities (Fig. 3a, b; Table 1). The main litter consumer on the FF was $N$. smithi, while $N$. asiaticum, $N$. malabaricum and $M$. tetragonum were more common in feeding on the leaves from the experimental plots placed in the ELF. The feeding activity of $N$. smithi, $N$. asiaticum and $N$. malabaricum were evenly distributed along the $24 \mathrm{~h}$ in both the sites, showing no temporal segregation among the species activity (Table 1 ). On the other hand, $M$. tetragonum showed to be more active at the ELF than at the FF site during the hottest hours of the day $(t=3.85, p<0.001$, post hoc test).

During our experiments, the total number of leaves collected by the experimental crabs after 1 hour of observation did not vary between the two sites (Pseudo- $F=1.35$, $\mathrm{df}=1, \mathrm{p}=0.25$; PERMANOVA test, Fig. 4) at different times of the day (Pseudo- $\mathrm{F}=0.39, \mathrm{df}=2, \mathrm{p}=0.68$; PERMANOVA test, Fig. 4). Overall, there was a strong difference in leaf removal among species, with the leaves of $R$. apiculata and Bruguiera spp. significantly more frequently removed over the ones of E. agallocha (SNK test, 

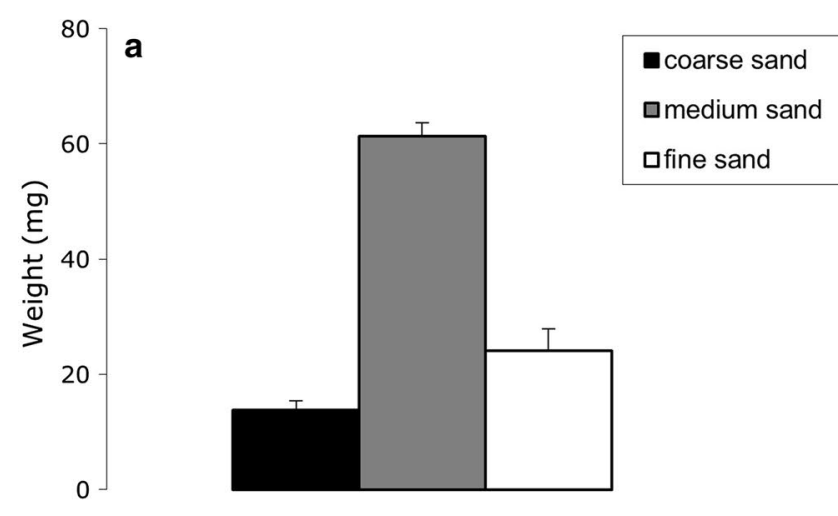

口fine sand

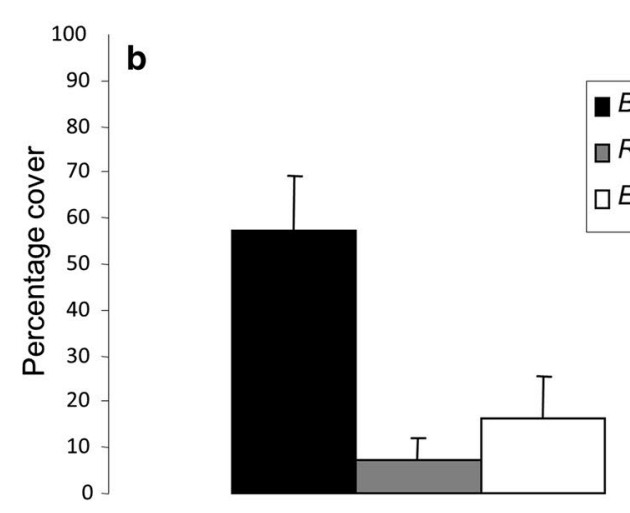

- Bruguiera spp.

$\square$ Rhizophora apiculata

$\square$ Excoecaria agallocha
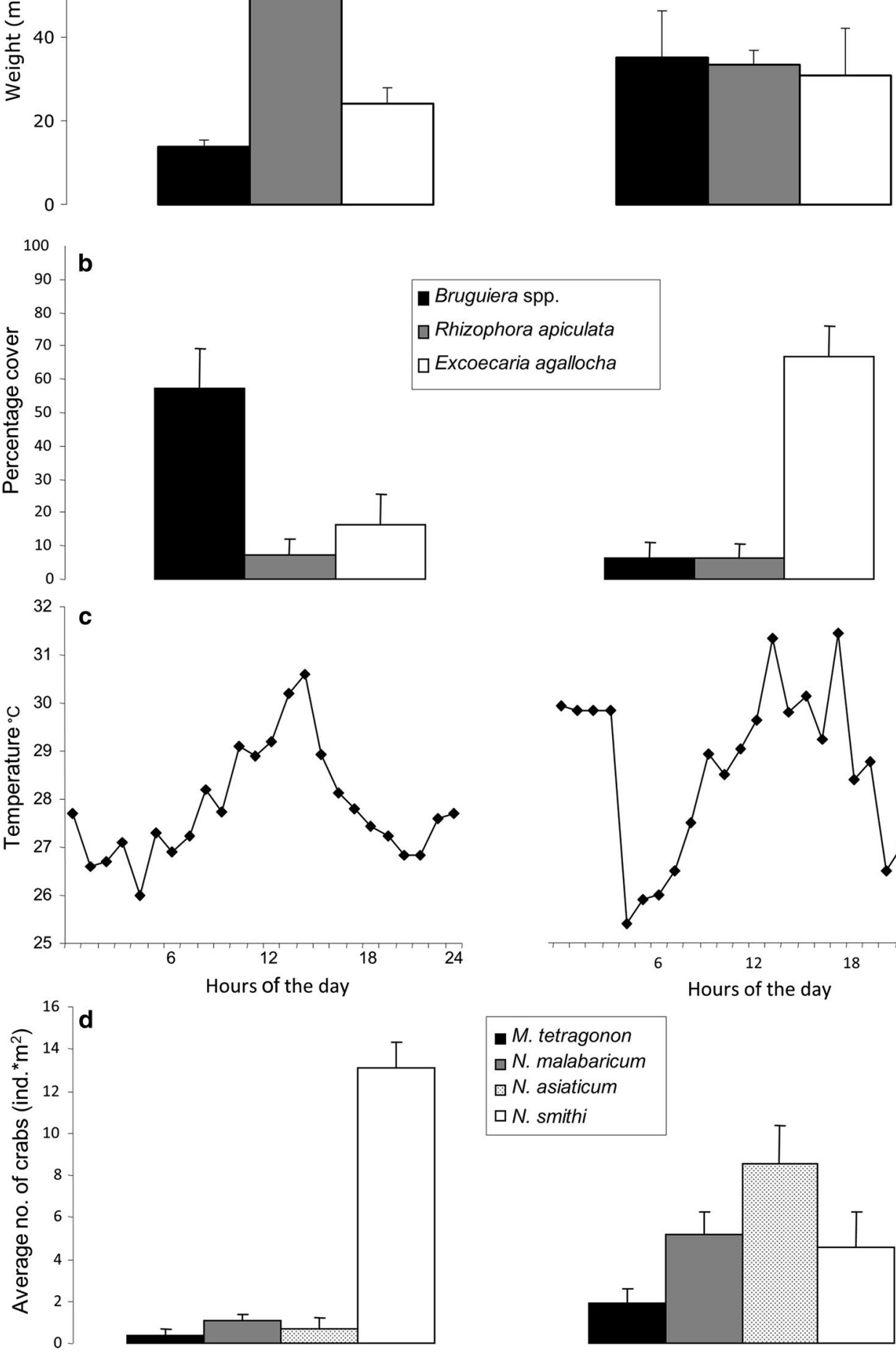

Forest floor

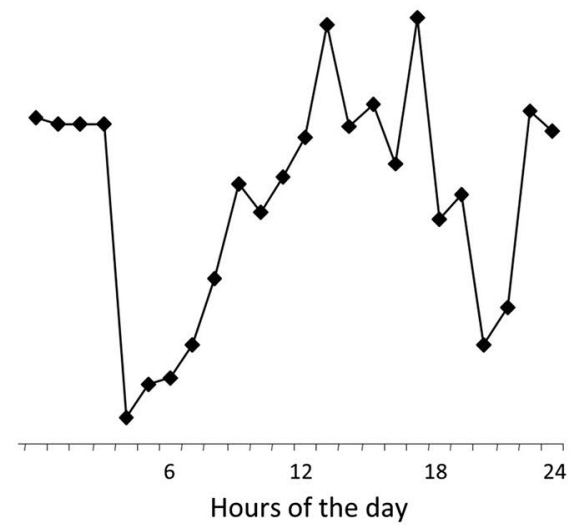

- M. tetragonon

$\square$ N. malabaricum

N N. asiaticum

$\square N$. smithi

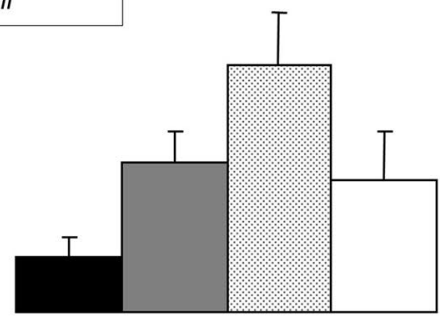

Elevated littoral fringe

Fig. 2 Characterisation of the two study sites. The soil texture (a), the percentage cover of the different trees (b), the pattern of surface temperature along the $24 \mathrm{~h}(\mathbf{c})$ and the abundance of the different crabs (d) are shown for the forest floor and the elevated littoral fringe, respectively 


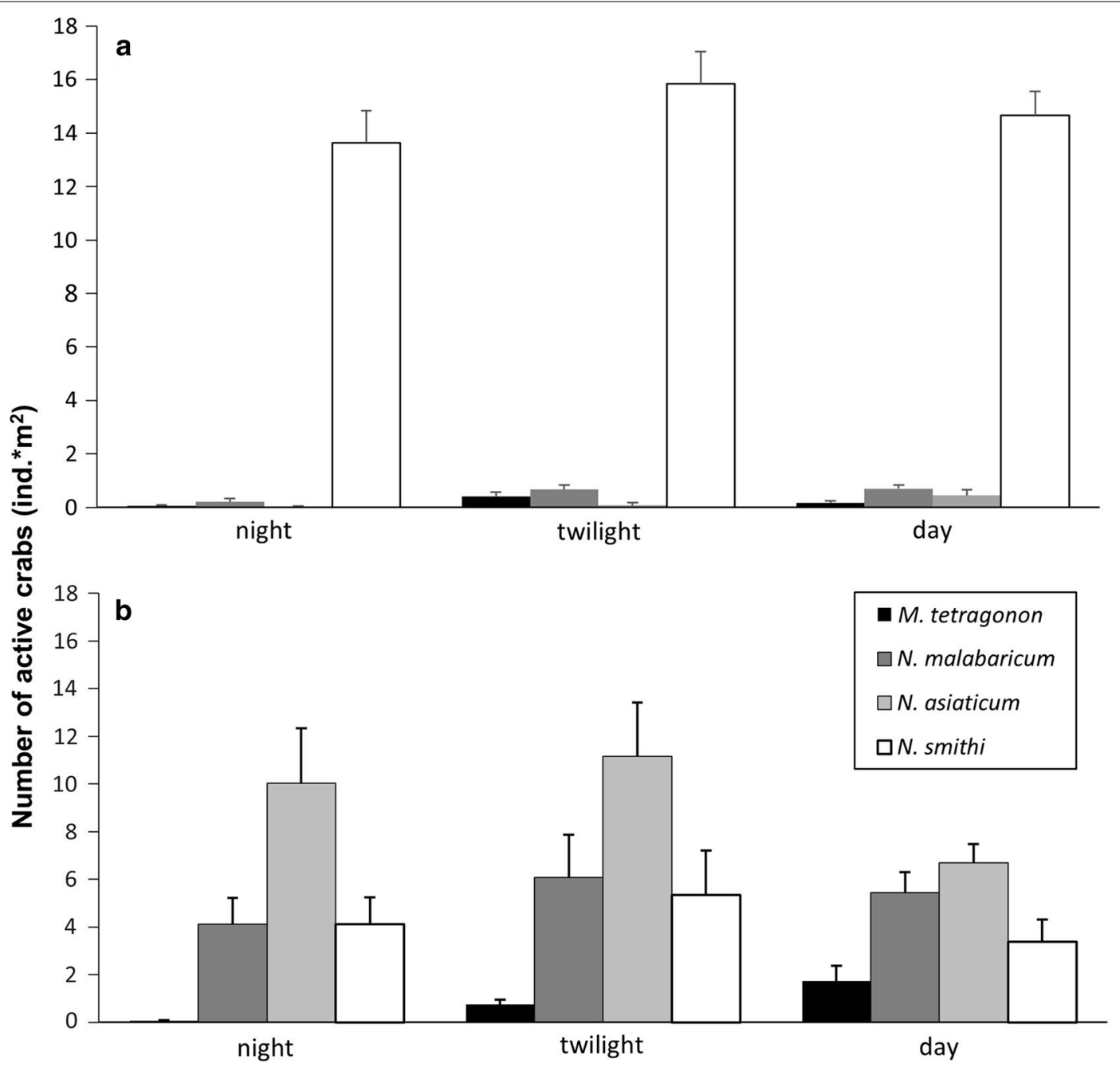

Fig. 3 Feeding activity of the four observed crab species as recorded on the forest floor (a) and at the elevated littoral fringe (b) during nocturnal, twilight and daytime hours

Table 1 Results of the two-way PERMANOVAs performed on the numbers of each experimental crab species feeding at the two study sites during different times of the day

\begin{tabular}{|c|c|c|c|c|c|c|c|c|c|c|c|c|c|}
\hline \multirow[t]{2}{*}{ Source } & \multirow[t]{2}{*}{ DF } & \multicolumn{3}{|c|}{ M. tetragonum } & \multicolumn{3}{|c|}{ N. malabaricum } & \multicolumn{3}{|c|}{ N. asiaticum } & \multicolumn{3}{|c|}{ N. smithi } \\
\hline & & MS & P-F & $\mathbf{P}$ & MS & P-F & $\mathbf{P}$ & MS & P-F & $P$ & MS & P-F & $\mathbf{P}$ \\
\hline Site (Si) & 1 & 4.88 & 17.97 & $<0.001$ & 32.64 & 79.39 & $<0.001$ & 61.63 & 96.89 & $<0.001$ & 69.24 & 96.96 & $<0.001$ \\
\hline Daytime (Dt) & 2 & 0.40 & 1.48 & 0.24 & 0.16 & 0.40 & 0.67 & 0.33 & 0.52 & 0.59 & 0.12 & 0.17 & 0.85 \\
\hline $\mathrm{Si} \times \mathrm{Dt}$ & 2 & 1.09 & 4.03 & 0.02 & 0.92 & 2.23 & 0.11 & 0.70 & 1.09 & 0.25 & 0.36 & 0.36 & 0.70 \\
\hline RES & 84 & 0.27 & & & 0.41 & & & 0.64 & & & 0.71 & & \\
\hline ТOT & 89 & & & & 89 & & & 89 & & & 89 & & \\
\hline
\end{tabular}

For each test and each factor (RES residuals), $D F$ the degrees of freedom, MS mean square, $P$ - $F$ values of Pseudo- $F$ statistic, $P$ the probability level, are shown

Table 2, Fig. 4). The removal of the Rhizophoraceae was constant over the day and did not change between the two sites (Table 2).
A total of 1671 leaves was collected by the crabs during the 15 days of observations and successfully stored in their burrows. We also observed a total of 121 intra- and 


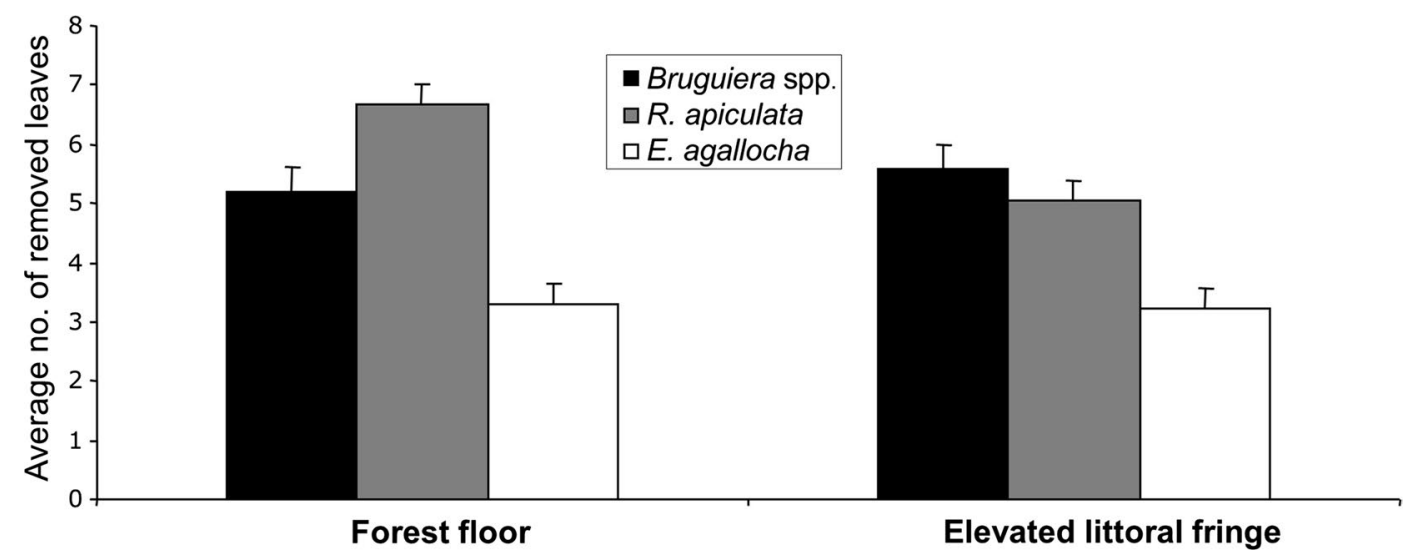

Fig. 4 Number of leaves of the different species collected in the experimental plots

Table 2 Results of the 3-factor ANOVA performed on leaves removal at the two experimental sites, within the different daytimes

\begin{tabular}{lcccc}
\hline Source & DF & MS & F & P \\
\hline Leaves (Le) & 2 & 2.15 & 21.17 & $<0.001$ \\
Site (Si) & 1 & 0.18 & 1.77 & 0.19 \\
Daytime (Dt) & 2 & 0.01 & 0.05 & 0.95 \\
Le $\times$ Si & 2 & 0.13 & 1.27 & 0.29 \\
Le $\times$ Dt & 4 & 0.07 & 0.7 & 0.60 \\
Si $\times$ Dt & 2 & 0.20 & 1.93 & 0.15 \\
Le $\times$ Si $\times$ Dt & 4 & 0.17 & 1.66 & 0.17 \\
RES & 72 & 0.10 & & \\
TOT & 89 & & &
\end{tabular}

$D F$ degrees of freedom, MS mean square, $F$ values of $F$ statistic, $P$ the probability level, are shown inter-specific agonistic interactions in which a leaf, previously collected by one crab, was stolen by another crab, which successfully stored it in its burrow. In the two habitats, these acts of agonistic competition had different characteristics, both in terms of species involved and number of interactions (Table 3). At the ELF (i.e. the densest site) we recorded a higher number of agonistic interactions than on the FF (82 and 39, respectively: Table 3). Moreover, at the ELF we observed fights involving all pairs of species present in the area, while on the FF intra-specific interactions were infrequent and some species pairs never interacted (Table 3). The number of leaves won from an opponent was proportional to the total number of leaves collected and stored in the burrows for each species at both intertidal levels $\left(\chi^{2}=3.59\right.$, $\mathrm{df}=3, \mathrm{p}=0.30$ and $\left.\mathrm{x}^{2}=2.02, \mathrm{df}=3, \mathrm{p}=0.56\right)$, showing that the number of agonistic interactions was related

Table 3 Feeding experiments and intra- and inter-specific agonistic interactions observed at the two intertidal levels

\begin{tabular}{|c|c|c|c|c|c|c|}
\hline \multicolumn{7}{|c|}{ Elevated littoral fringe } \\
\hline Feeder & TOT removed & Stolen & M. tetragonon & N. malabaricum & N. asiaticum & N. smithi \\
\hline M. tetragonon & $50(5.85 \%)$ & 4 & $1(25.0 \%)$ & 0 & $3(75.0 \%)$ & 0 \\
\hline N. malabaricum & 222 (26.03\%) & 14 & $1(7.1 \%)$ & $11(78.6 \%)$ & $2(14.3 \%)$ & 0 \\
\hline N. asiaticum & 422 (49.47\%) & 46 & $6(13 \%)$ & $18(39.1 \%)$ & $22(47.8)$ & 0 \\
\hline N. smithi & 159 (18.64\%) & 18 & $1(5.6 \%)$ & 7 (38.9\%) & 8 (44.4\%) & $2(11.1 \%)$ \\
\hline \multicolumn{7}{|l|}{ Forest floor } \\
\hline Feeder & TOT removed & Stolen & M. tetragonon & N. malabaricum & N. asiaticum & N. smithi \\
\hline M. tetragonon & 10 (1.17\%) & 0 & 0 & 0 & 0 & 0 \\
\hline N. malabaricum & $28(3.28 \%)$ & 0 & 0 & 0 & 0 & 0 \\
\hline N. asiaticum & $14(1.64 \%)$ & 1 & 0 & 0 & $1(100 \%)$ & 0 \\
\hline N. smithi & 766 (89.80\%) & 38 & $5(13.2 \%)$ & $6(15.8 \%)$ & 0 & $27(71.0 \%)$ \\
\hline
\end{tabular}

For each of the observed species (feeder), the total numbers of leaves removed (TOT removed), the numbers of leaves stolen from another crab in agonistic encounters (Stolen) and numbers (and percentages) of agonistic interactions for each pair of species are shown. 0 means no interactions between pairs of species 
to the frequencies of feeding activity. However, no species was able to steal a single leaf in 29 agonistic encounters involving as an opponent $N$. smithi, regardless of the intertidal area. At the ELF, $N$. asiaticum was the most successful in conquering a leaf in an aggressive contest, but it was never able to conquest a leaf from $N$. smithi (Table 3). The same was true for M. tetragonum and $N$. malabaricum that were often engaged in interactions for the leaves but never able to succeed when the opponent was a N. smithi. This latter species was the only one capable of winning agonistic interactions observed at FF site (Table 3).

\section{Discussion}

Our data showed how the direct anthropogenic influence on this Sri Lankan mangrove forest resulted in a true ecological modification of the area, with a clearly defined original forest, colonising the eulittoral zone, and a newly formed littoral fringe, which was promptly re-colonised by mangroves and crabs. We took advantage of this situation in planning this study, since tree and crab community composition and density in the new littoral fringe proved to be different from the lower eulittoral forest area. The elevated littoral fringe was a harsher environment respect to the mangrove forest floor due to almost no inundation periods, high surface temperature and by the dominance of E. agallocha, known to be a terrestrial mangrove associate [59]. However, in terms of crab assemblage, this habitat has been colonised by a denser and more diverse assemblage of litter-feeding sesarmid crabs than the forest floor. The smaller litter feeders $(M$. tetragonum and $N$. malabaricum) were definitely most abundant here, while the rest of the forest was strongly dominated by $N$. smithi.

The higher crab density recorded in the littoral fringe as opposed to the forest floor is rather unexpected, since this habitat has significantly lower tree cover than the forest and, consequently it provides lower amounts of litter, presumably resulting in a shortage of food for these sesarmids. Moreover, the elevated littoral fringe was dominated by $E$. agalloch $a$, which produces litter rich in a lattice poisonous for humans [59] and was by far the less eaten food among all the tested crab species. Although sesarmid crabs can rely on food sources other than leaf litter [22, 60-62], this is still the major component of their diet [see 21, 63-66]. Indeed, both shortage of litter and a diet based on litter of poor quality proved to have negative consequences on sesarmid crabs, as proved for Perisesarma messa [67] and for Parasesarma affine and Perisesarma bidens [68].

Thus, why we found a denser and more diverse assemblage of sesarmids at the man-made elevated littoral fringe than on the natural forest floor? And why were all the species except $N$. smithi more abundant in this unfavourable habitat? A reasonable explanation comes from the strong interference competition recorded during our feeding experiments with a noticeable highest aggressiveness and dominance showed by $N$. smithi towards the other litter-feeding species.

Inter- and intra-specific interference competition events appeared to be very frequent at both intertidal levels and throughout the $24 \mathrm{~h}$. All the study species showed to feed mainly on the same food, i.e. Rhizophoraceae leaves, and this unquestionably enhanced the direct competition for food. All species were also actively feeding at any time of the day, showing no temporal segregation, despite previous data from East Africa reported a preference for diurnal activity by N. smithi [69]. Virtually interference competition is almost always asymmetric, with some individuals/species dominating the others [70]. In our case, $N$. smithi individuals were always the dominant competitors at both areas, never being defeated in any inter-specific interactions. The dominance of $N$. smithi in gathering mangrove litter may prevent other species to colonise the forest floor and force them to move in a new habitat although less favourable. We, thus, suggest that the lower limit of zonation for $N$. asiaticum, $N$. malabaricum and $M$. tetragonum within our study area was primarily set by the competition for food with N. smithi.

Dominance is frequently related to the size and force of the opponents [21, 70-73]. Actually, N. smithi was not the largest of the species observed at our study site, since it is very similar in dimensions to $N$. asiaticum, and it is not endowed with any special "weapon" (i.e. the largest chelae: [71, 72]). Since during our observations we never observed an agonistic encounter towards $N$. smithi, we propose that the dominance of $N$. smithi can be due to its speed and readiness to exit its burrow, instead of its effective force (as already shown for other herbivorous mangrove crabs: [21]).

In intertidal ecology, it has been often reported that the lower limit of a species' distribution is determined by biotic factors, such as predation pressure and competition for limiting resources [74-76], while the upper limit is set by abiotic factors, such as temperature, salinity, and water supply [74-76]. Moreover, it is known that higher intertidal fringes expose animals to harsher abiotic conditions than lower intertidal areas [75], thus hosting, under competitive conditions, mainly inferior competitors [36, 77-79]. The present study is in line with the above results and indicates, for the first time in mangrove ecosystems, that interference competition for feeding resources may be a major force shaping the spatial distribution of sesarmids, setting their lower distributional limit. This biotic factor likely acts in synergy with abiotic factors, such as salinity, soil temperature and inundation time, that vary 
between the two experimental habitats and over the dry and wet seasons in Sri Lanka [80]. At the same time, we explain the low density of $N$. smithi in the less favourable elevated littoral fringe, hypothesising that its upper limit of distribution can be set by physical factors (elevated temperature, low humidity of the soil and high exposure to the sun light). Although nothing is known about the biology and physiology of $N$. asiaticum, M. tetrago$n u m$ and $N$. malabaricum, the seaward distribution of $N$. smithi all along the East African coast [81] and lower tolerance to changes in salinity recorded for $N$. smithi with respect to its east African congeneric $N$. africanum (old name $N$. meinerti [51]) [82] may suggest that $N$. smithi could be more vulnerable to harsh environments than other congeneric species and, more generally, than other sesarmids.

\section{Conclusions}

The historical hypotheses about the drivers of spatial distribution of sesarmids mostly imply a strong linkage between the litter-feeding species and their preferred trees $[6,7]$. Those hypotheses are barely corroborated by the vast literature on the subject, which shows how these herbivorous crabs exerted no or very weak preferences for different mangrove leaves [63, 65, 67]. Our data, in fact, cannot be explained by such theories, since all experimental crabs living in the E. agallocha-dominant littoral fringe avoided its leaves and may be thus facing food shortage.

The role of interference competition in shaping zonation and spatial distribution of mangrove crabs has been underestimated in mangrove ecology, and therefore our study is novel in enlightening a strong effect of this biological factor in structuring mangrove macrobenthic assemblages. However, we are also aware that our findings need to be corroborate by other field observations and trials. In particular, we recognise the importance of performing manipulative removal or exclusion experiments as historically done in other intertidal habitats [83], despite such an approach is very difficult or even impossible to be applied in mangroves with large sesarmid crabs $[84,85]$. Finally, this study adds interference competition for food as a key factor in the complex interplay of biotic (predation, competition for space) and abiotic environmental factors determining the spatial and distribution patterns of mangrove fauna.

\section{Authors' contributions}

SC and FD conceived and funded the study. SC, MF, FC, FD carried out the field work. SC, MF and SF participated in the data analyses. SF, SC and FD wrote the manuscript. All authors read and approved the final manuscript.

\section{Author details}

${ }^{1}$ The Swire Institute of Marine Science and the School of Biological Sciences, The University of Hong Kong, Pokfulam Road, Hong Kong, Hong
Kong SAR. ${ }^{2}$ Department of Biology, University of Florence, via Madonna del Piano 6, 50019 Sesto Fiorentino, Italy. ${ }^{3}$ Biological and Environmental Sciences and Engineering Division (BESE), King Abdullah University of Science and Technology (KAUST), Thuwal 23955-6900, Saudi Arabia. ${ }^{4}$ Laboratory of Systems Ecology and Resource Management, Université Libre de BruxellesULB, Av. F.D. Roosevelt 50, CPi 264/1, 1050 Brussels, Belgium. ${ }^{5}$ Laboratory of Plant Biology and Nature Management, Mangrove Management Group, Vrije Universiteit Brussel-VUB, Pleinlaan 2, 1050 Brussels, Belgium. ${ }^{6}$ Mangrove Specialist Group, IUCN Species Survival Commission, 28 rue Mauverney, 1196 Gland, Switzerland.

\section{Acknowledgements}

We thank Lucia Toccafondi, Riccardo Simoni and Valeria Tomasello for helping in the field work.

\section{Competing interests}

The authors declare that they have no competing interests.

\section{Availability of data and materials}

The datasets supporting the conclusions of this article are included within the article. Raw data are available from the corresponding author upon reasonable request.

\section{Consent to publish}

Not applicable.

\section{Ethics approval and consent to participate}

We declare that our experiments were performed in the respect of ethical rules.

\section{Funding}

Funds are from a FIRB project (Italian MIUR) "Mangrove fauna and flora: pattern of reproductive biology and dispersal mechanisms" to Stefano Cannicci and from the Belgian National Science Foundation and from the Flemish Interuniversity Council (VLIR) to Farid Dahdouh Guebas. Funding bodies had no role in the study design, in the collection, analysis and interpretation of data, in writing the manuscript or the decision to submit the paper for publication.

\section{Publisher's Note}

Springer Nature remains neutral with regard to jurisdictional claims in published maps and institutional affiliations.

Received: 6 July 2017 Accepted: 9 February 2018

Published online: 15 February 2018

\section{References}

1. Plaziat JC. Mollusk distribution in the mangal. In: Por D, Dor I, editors. Hydrobiology of the mangal: the ecosystem of the mangrove forests. Norwell: Boston; 1984. p. 111-43.

2. Fratini S, Vigiani V, Vannini M, Cannicci S. Terebralia palustris (Gastropoda; Potamididae) in a Kenyan mangal: size structure, distribution and impact on consuming leaf litters. Mar Biol. 2004;114:1173-82.

3. Cannicci S, Burrows D, Fratini S, Smith TJ III, Offemberg J, DahdouhGuebas F. Faunal impact on vegetation structure and ecosystem function in mangrove forests: a review. Aquat Bot. 2008:89:186-200.

4. Dev Roy MK. An annotated checklist of mangrove and coral reef inhabiting Brachyuran crabs of India. Rec Zool Surv India Occ Paper. 2008;289:1-212.

5. Tan CGS, Ng PKL. An annotated checklist of mangrove brachyuran crabs from Malaysia and Singapore. Hydrobiologia. 1994;285:75-84.

6. Macnae W. A general account of the fauna and flora of mangrove swamps and forests in the Indo-West-Pacific region. Adv Mar Biol. 1968;6:73-270.

7. Jones DA. Crabs of the mangal ecosystem. In: Por D, Dor I, editors. Hydrobiology of the mangal: the ecosystem of the mangrove Forests. Boston: Junk; 1984. p. 89-110. 
8. Sasekumar A. Distribution of macrofauna on a Malayan mangrove shore. J Anim Ecol. 1974:43:51-69.

9. Hartnoll RG. The Grapsidae and Ocypodidae (Decapoda:Brachyura) of Tanzania. J Zool. 1975;177:305-28.

10. Icely JD, Jones DA. Factors affecting the distribution of the genus Uca (Crustacea: Ocypodidae) on an East African shore. Estuar Coast Mar Sci. 1978;6:315-25

11. Macintosh DJ. The ecology and physiology of decapods of mangrove swamps. Symp Zool Soc Lond. 1988;59:315-41.

12. Dahdouh-Guebas F, Verneirt M, Cannicci S, Kairo JG, Tack JF, Koedam N. An exploratory study on grapsid crab zonation in Kenyan mangroves. Wetl Ecol Manag. 2002;10:179-87.

13. Lee SY. Mangrove macrobenthos: assemblages, services, and linkages. J Sea Res. 2008;59:16-29.

14. Shih H-T, Ng PKL, Davie PJF, Schubart CD, Türkay M, Naderloo R, Jones D, Liu M-Y. Systematics of the family Ocypodidae Rafinesque, 1815 (Crustacea: Brachyura), based on phylogenetic relationships, with a reorganization of subfamily rankings and a review of the taxonomic status of Uca Leach, 1814, sensu lato and its subgenera. Raffles Bull Zool. 2016;64:139-75

15. Edney EB. The water and heat relationships of fiddler crabs (Uca spp.). Trans R Soc S Afr. 1961;36:71-91.

16. Nobbs M, Blamires SJ. Spatiotemporal distribution and abundance of mangrove ecosystem engineers: burrowing crabs around canopy gaps. Ecosphere. 2015;6:84

17. Nobbs M, Blamires SJ. Fiddler crab spatial distributions are influenced by physiological stressors independent of sympatric interactions. J Exp Mar Biol Ecol. 2017;491:19-26.

18. Bezerra LEA, Dias CB, Santana GX, Matthews-Cascon H. Spatial distribution of fiddler crabs (genus Uca) in a tropical mangrove of northeast Brazil. Sci Mar. 2006;70:759-66.

19. Mokhtari M, Ghaffar MA, Usup G, Cob ZC. Determination of key environmental factors responsible for distribution patterns of fiddler crabs in a tropical mangrove ecosystem. PLoS ONE. 2015. https://doi.org/10.1371/ journal.pone.0117467.

20. Lee SY. Litter production and turnover of the mangrove Kandelia candel (L.) Druce in a Hong Kong tidal shrimp pond. Estuar Coast Shelf Sci. 1989;29:75-87.

21. Fratini S, Sacchi A, Vannini M. Competition for mangrove leaf litter between two East African crabs, Neosarmatium meinerti (Sesarmidae) and Cardisoma carnifex (Gecarcinidae): a case of kleptoparasitism? J Ethol. 2011:29:481-5

22. Sousa WP, Dangremond EM. Trophic interactions in coastal and estuarine mangrove forest ecosystems. Treatise Estuar Coast Sci. 2011;6:43-93.

23. Kristensen E, Alongi DM. Control by fiddler crabs (Uca vocans) and plant roots (Avicennia marina) on carbon, iron, and sulfur biogeochemistry in mangrove sediment. Limnol Oceanogr. 2006;51:1557-71.

24. Kristensen E. Mangrove crabs as ecosystem engineers; with emphasis on sediment processes. J Sea Res. 2008;59:30-43.

25. Penha-Lopes G, Bartolini F, Limbu S, Cannicci S, Kristensen E, Paula J. Are fiddler crabs potentially useful ecosystem engineers in mangrove wastewater wetlands? Mar Pollut Bull. 2009;58:1694-703.

26. Penha-Lopes G, Bartolini F, Limbu S, Cannicci S, Mgaya Y, Kristensen E, Paula J. Ecosystem engineering potential of the gastropod Terebralia palustris (Linnaeus, 1767) in mangrove wastewater wetlands: a controlled mesocosm experiment. Environ Pollut. 2010;158:258-66.

27. Bartolini F, Cimo F, Fusi M, Dahdouh-Guebas F, Lopes GP, Cannicci S. The effect of sewage discharge on the ecosystem engineering activities of two East African fiddler crab species: consequences for mangrove ecosystem functioning. Mar Environ Res. 2011;71:53-61.

28. Dahdouh-Guebas F, Verneirt M, Tack JF, Koedam N. Food preferences of Neosarmatium meinerti de Man (Decapoda:Sesarminae) and its possible effect on the regeneration of mangroves. Hydrobiologia. 1997;347:83-9.

29. Dahdouh-Guebas F, Verneirt M, Tack JF, Van Speybroeck D, Koedam N. Propagule predators in Kenyan mangroves and their possible effect on regeneration. Mar Freshw Res. 1998;49:345-50.

30. Bosire JO, Kazungu J, Koedam N, Dahdouh-Guebas F. Predation on propagules regulates regeneration in a high-density reforested mangrove plantation. Mar Ecol Prog Ser. 2005;299:149-55.
31. Andreetta A, Fusi M, Cameldi I, Cimo F, Carnicelli S, Cannicci S. Mangrove carbon sink. Do burrowing crabs contribute to sediment carbon storage? Evidence from a Kenyan mangrove system. J Sea Res. 2014;85:524-33.

32. Dahdouh-Guebas F, Koedam N, Satyanarayana B, Cannicci S. Human hydrographical changes interact with propagule predation behaviour in Sri Lankan mangrove forests. J Exp Mar Biol Ecol. 2011;399:188-200.

33. Paula J, Dornelas M, Flores AAV. Stratified settlement and moulting competency of brachyuran megalopae in Ponta Rasa mangrove swamp, Inhaca Island (Mozambique). Estuar Coast Shelf Sci. 2003;56:325-37.

34. Newell RC. Biology of intertidal organisms. 3rd ed. Kent: Marine Ecological Surveys, Ltd.; 1979

35. Benedetti-Cecchi L. Variability in abundance of algae and invertebrates at different spatial scales on rocky sea shores. Mar Ecol Progr Ser. 2001;215:79-92.

36. Tran MV, O'Grady M, Colborn J, Van Ness K, Hill RW. Aggression and food resource competition between sympatric hermit crab species. PLoS ONE. 2014. https://doi.org/10.1371/journal.pone.0091823.

37. Grover JP. Resource competition. London: Chapman and Hall; 1997.

38. Begon M, Harper JL, Townsend CR. Ecology: individuals, populations, and communities. 2nd ed. Oxford: Blackwell Scientific Publications; 1990.

39. Le Bourlot $\mathrm{V}$, Tully $T$, Claessen D. Interference versus exploitative competition in the regulation of size-structured populations. Am Nat. 2014;184:609-23.

40. Fretwell SD, Lucas HL. On territorial behaviour and other factors influencing habitat distribution in birds. Acta Biotheor. 1970;19:16-36.

41. Van Nedervelde F, Cannicci S, Koedam N, Bosire J, Dahdouh-Guebas F. What regulates crab predation on mangrove propagules? Acta Oecol. 2015;63:63-70.

42. Dayton PK. Competition, disturbance, and community organization: the provision and subsequent utilization of space in rocky intertidal community. Ecol Monogr. 1971;41:351-89.

43. Dahdouh-Guebas F, Verheyden A, De Genst W, Hettiarachchi S, Koedam $\mathrm{N}$. Four decade vegetation dynamics in Sri Lankan mangroves as detected from sequential aerial photography: a case study in Galle. Bull Mar Sci. 2000;67:741-59.

44. Jayatissa LP, Dahdouh-Guebas F, Koedam N. A review of the floral composition and distribution of mangroves in Sri Lanka. Bot J Linn Soc. 2002;138:29-43.

45. Satyanarayana B, Koedam N, De Smet K, Di Nitto D, Bauwens M, Jayatissa LP, Cannicci S, Dahdouh-Guebas F. Long-term mangrove forest development in Sri Lanka: early predictions evaluated against outcomes using VHR remote sensing and VHR ground-truth data. Mar Ecol Prog Ser. 2011:443:51-63.

46. Dahdouh-Guebas F, Koedam N. A synthesis of existent and potential mangrove vegetation structure dynamics from Kenyan, Sri Lankan and Mauritanian case-studies. Meded Zitt K Acad Overzeese Wet/Bull Séanc Acad R Sci Outre-Mer. 2002;48:487-511.

47. Satyanarayana B, Mulder S, Jayatissa LP, Dahdouh-Guebas F. Are the mangroves in the Galle-Unawatuna area (Sri Lanka) at risk? A social-ecological approach involving local stakeholders for a better conservation policy. Ocean Coast Manag. 2013;71:225-37.

48. Spalding M, Blasco F, Field C. World mangrove atlas. Okinawa: The International Society for Mangrove Ecosystems; 1997.

49. Dahdouh-Guebas F, Koedam N. Empirical estimate of the reliability of the use of the Point-Centred Quarter Method (PCOM): solutions to ambiguous field situations and description of the PCQM+ protocol. Forest Ecol Manag. 2006;228:1-18.

50. Ragionieri L, Fratini S, Vannini M, Schubart CD. Phylogenetic and morphometric differentiation reveal geographic radiation and pseudo-cryptic speciation in a mangrove crab from the Indo-West Pacific. Mol Phylogenet Evol. 2009:52:825-34.

51. Ragionieri L, Fratini S, Schubart CD. Revised taxonomy of the Neosarmatium meinerti complex (Decapoda: Brachyura, Sesarmidae) with the description of three pseudocryptic Indo-West Pacific species. Raffles B Zool. 2012;60:71-87.

52. Skov MW, Vannini M, Shunula JP, Hartnoll RG, Cannicci S. Quantifying the density of mangrove crabs: Ocypodidae and Grapsidae. Mar Biol. 2002;141:725-32.

53. Hartnoll RG, Cannicci S, Emmerson WD, Fratini S, Macia A, Mgaya Y, Porri F, Ruwa RK, Shunula JP, Skov MW, Vannini M. Geographic trends in mangrove crab abundance in East Africa. Wetl Ecol Manag. 2002;10:203-13. 
54. Rorandelli R, Gomei M, Vannini M, Cannicci S. Feeding and masking selection in Inachus phalangium (Decapoda, Majidae): dressing up has never been so complicated. Mar Ecol Progr Ser. 2007;336:225-33.

55. Anderson MJ. A new method for non-parametric multivariate analysis of variance. Austral Ecol. 2001;26:32-46.

56. Anderson MJ, ter Braak CJF. Permutation tests for multi-factorial analysis of variance. J Stat Comput Simul. 2003;73:85-113.

57. Anderson MJ, Gorley RN, Clarke KR. PERMANOVA + for PRIMER: guide to software and statistical methods. Plymouth: PRIMER-E Ltd.; 2008.

58. Hammer $\varnothing$, Harper DAT, Ryan PD. PAST: paleontological Statistics software package for education and data analysis. Paleontol Electron. 2001:41:9.

59. Tomlinson PB. The botany of mangroves. Cambridge: Cambridge University Press; 1986.

60. Micheli F. Feeding ecology of mangrove crabs in North Eastern Australia: mangrove litter consumption by Sesarma messa and Sesarma smithii. J Exp Mar Biol Ecol. 1993;171:165-86.

61. Lee SY. Ecological role of grapsid crabs in mangrove ecosystems: a review. Mar Freshw Res. 1998:49:335-43.

62. Skov MW, Hartnoll RG. Paradoxical selective feeding on a low nutrient diet: why do mangrove crabs eat leaves? Oecologia. 2002;131:1-7.

63. Nordhaus I, Salewski T, Jennerjahn TC. Food preferences of mangrove crabs related to leaf nitrogen compounds in the Segara Anakan Lagoon, Java, Indonesia. J Sea Res. 2011;65:414-26.

64. Steinke TD, Rahj A, Holland AJ. The feeding behaviour of the red mangrove crab Sesarma meinerti De Man, 1887 (Crustacea: Decapoda: Grapsidae) and its effect on the degradation of mangrove leaf litter. S Afr J Mar Sci. 1993;13:151-60.

65. Micheli F, Gherardi F, Vannini M. Feeding and burrowing ecology of two east African mangrove crabs. Mar Ecol. 1991;111:247-54.

66. Thongtham N, Kristensen E. Carbon and nitrogen balance of leaf-eating sesarmid crabs (Neoepisesarma versicolor) offered different food sources. Estuar Coast Shelf Sci. 2005;65:213-22.

67. Micheli F. Effect of mangrove litter species and availability on survival, moulting, and reproduction of the mangrove crab Sesarma messa. J Exp Mar Biol Ecol. 1993:171:149-63.

68. Lee SY, Kwok PW. The importance of mangrove species association to the population biology of the sesarmine crabs Parasesarma affinis and Perisesarma bidens. Wetl Ecol Manag. 2002;10:215-26.

69. Fratini S, Cannicci S, Vannini M. Competition and interaction between Neosarmatium smithi (Crustacea: Grapsidae) and Terebralia palustris (Mollusca: Gastropoda) in a Kenyan mangrove. Mar Biol. 2000;137:309-16.

70. Smallegange IM, van der Meer J. Interference from a game theoretica perspective: shore crabs suffer most from equal competitors. Behav Ecol. 2006:18:215-21.

71. Sneddon LU, Huntingford FA, Taylor AC. Weapon versus body size as a predictor of winning on fights between shore crabs, Carcinus maenas (L.) Behav Ecol Sociobiol. 1997;41:237-42.
72. Schroeder L, Huber R. Fight strategies differ with size and allometric growth of claws in crayfish Orconectes rusticus. Behaviour. 2001;138:1437-49.

73. Yoshino K, Koga T, Oki S. Chelipeds are the real weapon: cheliped size is a more effective determinant than body size in male-male competition for mates in a hermit crab. Behav Ecol Sociobiol. 2011;65:1825-32.

74. Connell JH. The influence of intra-specific competition and other factors on the distribution of the barnacle Chthamalus stellatus. Ecology. 1961:42:710-23.

75. Raffaelli D, Hawkins SJ. Intertidal ecology. London: Springer Science \& Business Media; 2012

76. Somero GN. Thermal physiology and vertical zonation of intertidal animals: optima, limits, and cost of living. Integr Comp Biol. 2002;42:780-9.

77. Stillman JH, Somero GN. Adaptation to temperature stress and aerial exposure in congeneric species of intertidal porcelain crabs (genus Petrolisthes): correlation of physiology, biochemistry and morphology with vertical distribution. J Exp Biol. 1996;199:1845-55.

78. Bulleri F, Benedetti-Cecchi L, Acunto S, Cinelli F, Hawkins SJ. The influence of canopy algae on vertical patterns of distribution of low-shore assemblages on rocky coasts in the northwest Mediterranean. J Exp Mar Biol Ecol. 2002;267:89-106.

79. Mangialajo L, Chiantore M, Susini ML, Meinesz A, Cattaneo-Vietti R, Thibaut T. Zonation patterns and interspecific relationships of fucoids in microtidal environments. J Exp Mar Biol Ecol. 2012:412:72-80.

80. Dahdouh-Guebas F, Kairo JG, Jayatissa LP, Cannicci S, Koedam N. An ordination study to view vegetation structure dynamics in disturbed and undisturbed mangroves forests in Kenya and Sri Lanka. Plant Ecol. 2002;2002(161):123-35

81. Cannicci S, Bartolini F, Dahdouh-Guebas F, Fratini S, Litulo C, Macia A Mrabu EJ, Penha-Lopes G, Paula J. Effects of urban wastewater on crab and mollusc assemblages in equatorial and subtropical mangroves of East Africa. Estuar Coast Shelf. 2009;84:305-17.

82. Gillikin DP, De Wachter B, Tack JF. Physiological responses of two ecologically important Kenyan mangrove crabs exposed to altered salinity regimes. J Exp Mar Biol Ecol. 2004;301:93-109.

83. Paine RT. Intertidal community structure: experimental studies on the relationship between a dominant competitor and its principal predator. Oecologia. 1974;15:93-120

84. Pülmanns N, Mehlig U, Nordhaus I, Saint-Paul U, Diele K. Mangrove crab Ucides cordatus removal does not affect sediment parameters and stipule production in a one year experiment in Northern Brazil. PLoS ONE. 2016:11:e0167375. https://doi.org/10.1371/journal.pone.0167375.

85. Smith TJ III, Boto KG, Frusher SD, Giddins RL. Keystone species and mangrove forest dynamics: the influence of burrowing by crabs on soil nutrient status and forest productivity. Estuar Coast Shelf Sci. 1991;33:419-32.

\section{Submit your next manuscript to BioMed Central and we will help you at every step:}

- We accept pre-submission inquiries

- Our selector tool helps you to find the most relevant journal

- We provide round the clock customer support

- Convenient online submission

- Thorough peer review

- Inclusion in PubMed and all major indexing services

- Maximum visibility for your research

Submit your manuscript at www.biomedcentral com/submit 